\title{
Analysis Control Of Inventory Of Non Subsidy Fertilizer Merchandise With Economic Order Quantity (EOQ) Method In CV. Dohar Agro Mandiri
}

\section{Analisis Pengendalian persediaan Barang Dagang Pupuk Non Subsidi Dengan Metode Economic Order Quantity (EOQ) pada CV. Dohar Agro Mandiri}

\author{
Ferza Dwianda Afrimarsa ${ }^{1)}$; Neri Susanti 2); Tito Irwanto ${ }^{3)}$ \\ 1)Study Program of Accounting Faculty of Economic, Universitas Dehasen Bengkulu \\ 2) Faculty of Economic, Universitas Dehasen Bengkulu \\ Email: ${ }^{1)}$ ferza12@gmail.com
}

How to Cite :

Afrimarsa F., Susanti. N., Irwanto. T. (2021). Analysis Control Of Inventory Of Non Subsidy Fertilizer Merchandise With Economic Order Quantity (EOQ) Method In CV. Dohar Agro Mandiri. Jurnal Ekonomi Manajemen Akuntansi Dan Keuangan, 3(1). DOI: https://doi.org/10.53697/emak.v3i1

\section{ARTICLE HISTORY}

Received [1 Desember 2021]

Revised [10 Desember 2021]

Accepted [28 Desember 2021]

\section{KEYWORDS}

:Economic Order Quantity

(EOQ), Safety Stock (SS),

Reorder Point(ROP)

This is an open access article under the $C C-B Y$-SA license

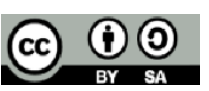

\section{ABSTRAK}

Economic order quantity(EOQ) adalah model numerik yang menentukan jumlah barang yang harus diminta untuk memenuhi kebutuhan yang diperpanjang, dengan biaya persediaan yang terbatas. Jenis biaya untuk mempertahankan siklus bisnis adalah biaya kapasitas dan biaya permintaan. Alasan dilakukannya tinjauan ini adalah untuk mengkaji "Pemeriksaan Pengendalian Stok Produk pupuk Non subsidi Dengan Teknik Economic order quantity(EOQ) Pada CV. Dohar Agro Mandiri.

Pengadaan all out stock menggunakan teknik EOQ adalah 11.003 dengan menggunakan pengulangan pembelian beberapa kali. Dengan menggunakan strategi EOQ organisasi harus melakukan pemesanan ulang pada jam stok produk sebanyak 1.015 zak, dengan teknik EOQ stok terbesar yang harus dimiliki organisasi adalah 12.018 setiap harinya. Biaya stok absolut stok pupuk adalah 24.648 dalam istilah yang berbeda, kontrol stok menggunakan strategi EOQ dapat membantu organisasi dengan mencapai tingkat permintaan stok dan permintaan berulang yang ideal.

\section{ABSTRACT}

Economic Order Quantity (EOQ) is a mathematical model that determines the number of items that must be ordered to meet the projected demand, with minimized inventory costs. The types of costs to run the business cycle are storage costs and ordering costs. The purpose of this research is to analyze "Analysis of NonSubsidized Fertilizer Inventory Control with Economic Order Quantity (EOQ) Method at CV. Dohar Agro Mandiri.

The total inventory obtained using the EOQ method is 11,003 with a purchase frequency of 3 times. Using the EOQ method the company must reorder when the merchandise inventory is 1,015 zak, with the EOQ method the maximum inventory that the company must maintain is 12,018 per day. The total inventory cost of fertilizer 
merchandise inventory is 24,648 . In other words, inventory control using the EOQ method can help companies achieve an optimal level of inventory ordering and ordering frequency..

\section{PENDAHULUAN}

Persediaan ialah salah satu aspek berguna dalam kegiatan berusaha, baik industri dagang ataupun manufaktur.Persediaan merupakan aspek krusial pada suatu industri dagang sebab persediaan memastikan aktivitas pembedahan industri.Jumlah persediaan barang yang sangat besar maupun kecil hendak menyebabkan bermacam permasalahan.bersumber pada perihal tersebut, hingga diharapkan sesuatu sistem pengadaan barang dagang yang baik dimana permintaan barang dagang bergantung dari jumlah permintaan konsumen.

Pengendalian persediaan sangat berarti buat penuhi kebutuhan pelanggan, sistem pencatatan di persediaan hendak terus membagikan seberapa besarnya nilai stok pada persediaan benda dagang yang terdapat digudang buat tiap- tiap tipe pupuk, dalam proses pengukuran persediaan membutuhkan perencanaan yang matang dan wajib cermat biar dalam persediaan benda tidak memunculkan resiko- resiko, ialah semacam efek kelebihan benda dagang. Hingga butuh diadakan analisa persediaan minimum pada industri dan bisa mengenakan tata cara Economic Order Quantity( EOQ) saat sebelum melaksanakan pemesanan benda.

CV. Dohar Agro mandiri yakni salah satu dari sebagian Industri yang berkecimpung dibidang distributor pupuk Non Subsidi yang terletak pada Provinsi Bengkulu.di Industri Cv. Dohar Agro mandiri Pengelolaan informasi Persediaan pupuk non subsidi dikala ini memakai aplikasi microsoft excel yang terdiri dari tabel- tabel. Informasi yang sudah ditulis hendak di input ke microsoft excel jadi laporan Persediaan Pupuk Non Subsidi. Perihal ini menciptakan distributor pupuk bekerja 2 kali serta memakan waktu yg relatif lama buat mengenali data persediaan pupuk sehingga dinilai tidak efisien dan tidak efektif

\section{LANDASAN TEORI}

\section{Persediaan}

Handoko( 2015) mengatakan kalau persediaan( inventory) merupakan sesuatu sebutan universal yang mengambarkan seluruh suatu ataupun sumber daya- sumber daya organisasi yang ditaruh dalam antisipasinya terhadap pemenuhan permintaan. dari teori ini penulis merumuskan persediaan maksudnya sesuatu sumber energi yang dapat ditaruh buat mengestimasi terdapatnya permintaan yang besar dari konsumen.

\section{Pengendalian persediaan}

Penafsiran pengendalian persediaan bagi Rusdiana( 2014: 381) melaporkan kalau“ Pengendalian persediaan maksudnya kegiatan mempertahankan jumlah persediaan pada tingkatan yang dihendaki". Tujuan dan Guna Pengendalian Persediaan:

1.Melindungi supaya jangan hingga industri kehilangan persediaan selaku dampaknya menimbulkan terhentinya kegiatan penciptaan.

2.Melindungi supaya pembuatan persediaan oleh organisasi tidak sangat besar ataupun berlebihlebihan, sehingga bayaran yang terdapat tidak sangat besar.

3.Melindungi biar pembelian secara kecil- kecilan bisa dihindari sebab ini hendak berdampak bayaran pemesanan terus menjadi besar.

\section{Economic Order Quantity (EOQ)}

Pengertian pengendalian persediaan sebagaimana ditunjukkan oleh Rusdiana (2014:381) menyatakan bahwa "Pengendalian persediaan mengandung arti tindakan menjaga agar persediaan

82 | Ferza Dwianda Afrimarsa, Neri Susanti, Tito Irwanto; Analysis Control Of Inventory... 
tetap pada tingkat yang ideal". Target dan Kapasitas Kontrol Stok:

1. Berhati-hatilah agar organisasi tidak kehabisan stok karena menyebabkan berakhirnya latihan pembuatan.

2. Menjaga agar pengembangan stok oleh asosiasi tidak terlalu besar atau tidak wajar, sehingga pengeluaran saat ini tidak terlalu besar.

3. Menahan pembelian dalam skala terbatas dapat dihindari karena hal ini akan menimbulkan biaya permintaan yang lebih tinggi.

EOQ atau $Q^{*}=\frac{\sqrt{2 . D . S}}{H}$

Dimana:

$\mathrm{Q}=$ Jumlah unit per pesanan

$Q^{*}=$ Jumlah optimum unit per pesanan

$\mathrm{D}=$ Penggunaan atau permintaan permintaan tahunan dalam unit

$\mathrm{S}=$ Biaya pemesanan untuk setiap pesanan

$\mathrm{H}=$ Biaya penyimpanan per unit per tahun

Manfaat Jumlah Permintaan Keuangan (EOQ):

1. Batas Squander dan Tidak Tersedia

2. Bantuan instance Berbagai Item

Kekurangan Jumlah Permintaan Keuangan (EOQ):

1. Pengukur nilai yang konsisten, Ide ini bergantung pada pengukur bahwa minat terhadap barang tersebut akan stabil secara konsisten.

2. Pada saat Conveyance Orders bisa berbeda, ide ini mengharapkan stok akan diperbarui dalam sekali jalan dari waktu ke waktu. Buy Recurrence.

Perulangan permintaan seperti yang diungkapkan oleh Deanta dalam Rifqi (2012:40) dapat dibentuk sebagai berikut:

$\mathrm{I}=\frac{D}{E O Q}$

Keterangan:

I = frekuensi pembelian dalam satu tahun

$\mathrm{D}=$ jumlah kebutuhan bahan baku selama satu tahun

$\mathrm{EOQ}=$ jumlah pembelian bahan sekali pesan

\section{Persediaan Pengaman (Safety Stock)}

Menurut gambaran Irham Fahmi (2016:121) persediaan kesejahteraan berarti kemampuan organisasi untuk mengatur kondisi persediaan yang selalu terlindungi atau penuh dengan keamanan dengan harapan perusahaan tidak akan pernah mengalami kekurangan persediaan. dapat dirinci sebagai berikut:

SS = Rata-rata Keterlambatan barang $x$ Kebutuhan barang dagang per hari

Titik Pemesanan Kembali atau Reorder Point (ROP)

Seperti yang ditunjukkan oleh Heizer, Render (2015: 98), "reorder point (ROP) adalah titik atau cutoff dari ukuran stok yang dapat diakses pada saat di mana pesanan harus dipertahankan. Untuk menentukan titik pemesanan ulang dapat ditentukan menggunakan yang menyertainya.Rumusnya sebagai berikut:

Keterangan:

$$
R O P=d \times L
$$

ROP : titik pemesanan kembali

$D$ : Kebutuhan barang dagang perhari 
L: waktu tunggu pesanan baru dalam hari

Total Biaya Persediaan atau Total Inventory Cost (TIC)

untuk mengetahui berapa biaya absolut persediaan yang terdiri dari biaya pembelian bahan mentah, biaya permintaan komponen mentah, dan biaya kapasitas. persamaannya adalah:

Keterangan:

$$
\left.\mathrm{TIC}=\left(\frac{D}{Q} S\right)+\frac{\mathrm{Q} *}{2} H\right)
$$

$Q^{*}=$ jumlah barang setiappemesanan

$\mathrm{D}=$ Permintaan tahunan barang persediaan, dalam unit

$S=$ biaya pemesanan untuk setiap pemesanan

\section{METODE PENELITIAN}

Penelitian ini menggunakan jenis eksplorasi serupa dengan menggunakan metodologi kuantitatif. Strategi logis yang digunakan adalah teknik yang relatif jelas.Strategi yang berbeda adalah jenis eksplorasi yang ditujukan untuk menggambarkan latihan terus menerus. Teknik pemilahan informasi adalah sebagai berikut::

1. Studi dokumen

2. Dokumentasi

3. Wawancara (Interview)

\section{HASIL PENELITIAN DAN PEMBAHASAN}

Dari tabel 1. di bawah diketahui bahwa perolehan all out stock yang diselesaikan menggunakan teknik EOQ adalah 11.003 dengan menggunakan pengulangan pembelian beberapa kali. Dalam keadaan organisasi yang sebenarnya, organisasi tidak menyimpulkan ukuran safetystockdan reorder point, sedangkan pada teknik EOQ, organisasi wajib memberikan safetystock dan reorder point. seperti yang ditunjukkan oleh hasil perhitungan, diketahui ukuran safety stock yang dibutuhkan Cv. Dohar Agro Mandiri hanya sekitar 609 zak.

Tabel 1. All Out Stok

\begin{tabular}{|l|l|c|}
\hline NO. & \multicolumn{1}{|c|}{ KETERANGAN } & METODE EOQ \\
\hline 1 & Pemesanan barang dagang optimal & 11.003 \\
\hline 2 & Frekuensi Pesanan Optimal & 3 \\
\hline 3 & Persediaan pengaman & 609 \\
\hline 4 & Pemesanan kembali & 1.015 \\
\hline 5 & Penentuan persediaan maksimum & 12.018 \\
\hline & Total Biaya persediaan & $\mathbf{2 4 . 6 4 8}$ \\
\hline
\end{tabular}

Dengan adanya safety stockakan sangat mempengaruhi usaha organisasi untuk mengikuti kelancaran proses usaha. Jika perusahaan sedang mempertimbangkan pilihan untuk mendapatkan stok kesejahteraan.Organisasi dapat menghindari bahaya kehabisan produk dengan asumsi ada masalah yang dapat mengambil langkah untuk mengganggu siklus bisnis, misalnya kekurangan produk atau penyedia terlambat menyampaikan permintaan stok.dengan memanfaatkan teknik EOQ organisasi diharuskan mengajukan permintaan kembali saat stok produk 1.015 zak. Artinya ketika stok produk benar-benar habis, susunan produk yang telah diminta selama 3 hari terakhir telah muncul di pusat distribusi sehingga interaksi bisnis tidak perlu berhenti karena penangguhan di penyedia yang menyampaikan pesanan barang dagangan menggunakan Dalam teknik EOQ, stok

84 | Ferza Dwianda Afrimarsa, Neri Susanti, Tito Irwanto; Analysis Control Of Inventory... 
terbesar yang harus dimiliki organisasi adalah sebanyak 12.018 per hari. Stok terbesar harus dimanfaatkan sebagai kontrol stok di Cv. Dohar Agro Mandiri karena dengan stok paling ekstrim perusahaan dapat menangani stok produk sehingga tidak ada penumpukan barang di gudang. Total biaya stok menggunakan teknik EOQ dapat dilihat bahwa total biaya stok kompos adalah 24.648 menggunakan istilah yang berbeda kontrol stok dengan strategi EOQ dapat membantu organisasi mencapai tingkat permintaan stok dan pengulangan permintaan yang ideal, bergabung dengan stok keamanan, fokus pemesanan ulang ( reorder point) dan stok paling ekstrim ( stok terbesar ) yang dapat sangat mempengaruhi upaya organisasi untuk membatasi pengeluaran stok produk

\section{Koefisien Determinasi}

Koefisien determinasi $\left(\mathrm{R}^{2}\right)$ pada intinya mengukur seberapa jauh kemampuan model dalam menerangkan variasi variabel dependen. Nilai koefisien determinasi adalah antara nol sampai satu $\left(0<\mathrm{R}^{2}<1\right)$. Nilai $\mathrm{R}^{2}$ yang kecil berarti kemampuan variabel-variabel independen dalam menjelaskan variasi variabel dependen sangat terbatas. Nilai yang mendekati satu berarti variabel-variabel independen memberikan hampir semua informasi yang dibutuhkan untuk memprediksi variasi variabel dependen.

\section{Pengujian Hipotesis}

a. Uji $t$

Uji t digunakan untuk mengetahui apakah variabel pengaruh atau independen secara parsial/ masing-masing mempengaruhi variabel terpengaruh atau dependen. pengujian dilakukan dengan menggunakan tingkat signifikasi sebesar 0,05.

b. Uji $F$

Uji F digunakan untuk mengetahui apakah variabel pengaruh/ independen secara bersama-sama atau simultan mempengaruhi variabel terpengaruh/ dependen

\section{HASIL DAN PEMBAHASAN}

\section{Analisis Regresi Linier Berganda}

Analisis regresi linier berganda digunakan untuk mengetahui besarnya pengaruh motivasi dan kepuasan kerja terhadap produktivitas kerja karyawan pada PT. Empat Lawang Agro Perkasa di Kabupaten Empat Lawang. Perhitungan statistik dalam analisis regresi berganda (Lampiran 5) dijelaskan pada tabel 2 berikut ini :

Tabel 2. Hasil Uji Regresi Berganda

Coefficients $^{\mathrm{a}}$

\begin{tabular}{|c|c|c|c|c|c|c|}
\hline \multirow{2}{*}{\multicolumn{2}{|c|}{ Model }} & \multicolumn{2}{|c|}{ Unstandardized Coefficients } & \multirow{2}{*}{\begin{tabular}{|c|} 
Standardized Coefficients \\
Beta
\end{tabular}} & \multirow[b]{2}{*}{ t } & \multirow[b]{2}{*}{ Sig. } \\
\hline & & B & Std. Error & & & \\
\hline \multirow[t]{3}{*}{1} & (Constant) & 1.501 & 5.900 & & .254 & .801 \\
\hline & Motivasi kerja & .380 & .157 & .3 & 2.424 & .021 \\
\hline & Kepuasan kerja & .603 & .185 & .4 & 3.258 & .003 \\
\hline
\end{tabular}

a. Dependent Variable: Produktivitas kerja

Sumber: Output SPSS Versi 21.0, 2021

Dari hasil Tabel 2 koefisien regresi menunjukkan nilai koefisien dalam persamaan regresi linier berganda. Nilai persamaan yang dipakai adalah yang berada pada kolom B (koefisien). Standar persamaan regresi linier berganda dapat diperoleh hasil sebagai berikut:

$\mathrm{Y}=1,501+0,380 \times 1+0,603 \times 2+5,900$

Persamaan regresi tersebut dapat dijelaskan sebagai berikut : 
1. Nilai konstanta 1,501 mempunyai arti bahwa apabila variabel Motivasi (X1) dan kepuasan kerja (X2) dianggap sama dengan nol (0) maka variabel produktivitas kerja $(\mathrm{Y})$ akan tetap sebesar 1,501 .

2. Pengaruh Motivasi ( $\mathrm{X} 1)$ terhadap produktivitas kerja $(\mathrm{Y})$. Nilai koefesien regresi variabel $\mathrm{X} 1$ (Motivasi) adalah sebesar 0,380, dengan asumsi apabila X1 (Motivasi) mengalami peningkatan sebesar satu-satuan, maka $\mathrm{Y}$ (Produktivitas kerja) juga akan mengalami peningkatan sebesar 0,380 .

3. Pengaruh Kepuasan kerja $(\mathrm{X} 2)$ terhadap Produktivitas kerja $(\mathrm{Y})$. Nilai koefesien regresi variabel X2 (kepuasan kerja) adalah sebesar 0,603, dengan asumsi apabila X2 (kepuasan kerja) mengalami peningkatan sebesar satu-satuan maka $\mathrm{Y}$ (produktivitas kerja) akan mengalami peningkatan sebesar 0,603.

\section{KESIMPULAN DAN SARAN}

\section{Kesimpulan}

Jika Anda menggunakan strategi EOQ, Anda dapat menghindari bahaya kehabisan produk karena perusahaan menentukan jumlah persediaan keamanan dan titik pemesanan kembali di mana hal ini akan sangat mempengaruhi upaya perusahaan untuk mengikutinya. proses transaksi yang lancar, seperti halnya stok organisasi yang paling ekstrem. dapat menangani stok barang dagangan sehingga tidak terjadi agregasi produk di pusat distribusi.

\section{Saran}

1. Bagi organisasi, konsekuensi dari review ini dapat dimanfaatkan sebagai bahan pemikiran bagi organisasi untuk meningkatkan inventory.

2. Bagi para spesialis masa depan, apa yang akan terjadi dalam eksplorasi ini dapat dijadikan semacam perspektif dan tolak ukur untuk pemeriksaan total di masa mendatang.

3. Bagi kalangan perguruan tinggi, ujian ini dapat dijadikan sebagai tambahan eksplorasi baru dengan memanfaatkan strategi EOQ.

\section{DAFTAR PUSTAKA}

Ahyari, Agus. 2012. Manajemen Produksi: Perencanaan Sistem Produksi. Yogyakarta : BPFE UGM.

Akbar, Muhammad. 2018. Analisis Persediaan Barang Dagang Menggunakan Metode EOQ (Economic Order Quantity) Pada PT. Mulia Prima Sentosa. Skripsi. Medan: Universitas Medan Area

Assauri, Sofyan. 2010. Manajemen Pemasaran. edisi pertama, cetakan kedelapan, Penerbit : Raja Grafindo, Jakarta.

A. Rusdiana M, \& Moch. Irfan, S. M. 2014. Sistem Informasi Manajemen. Bandung: Pustaka Setia.. Fahmi, I. 2016. Manajemen Produksi Dan Operasi. Penerbit: Alfabeta, Bandung.

Fajrin, Eldwidho Hanarista. 2015. Analisis Pengendalian Persediaan Bahan Baku Dengan Menggunakan Metode Economic Order Quantity (EOQ) Pada Perusahaan Roti Bonansa. Skripsi. Semarang: Universitas Negeri Semarang.

Handoko, T. Hani, 2015. Dasar-dasar Manajemen Produksi dan Operasi. Edisi I. BPFE Yogyakarta.

Heizer, Jay dan Barry, Render. 2015. Operations Management: Manajemen Operasi. Buku 2. Edisi Kesembilan. Jakarta: Salemba Empat.

Herjanto, Eddy. 2015. Manajemen Operasi. Edisi Ketiga, Jakarta: Grafindo.

Ikatan Akuntansi Indonesia, 2015. Standar Akuntansi Keuangan, Penerbit Salemba Empat, Jakarta.

Ikatan Akuntan Indonesia. 2013. Standar Akuntansi Keuangan Entitas Tanpa Akuntabilitas Publik (SAK ETAP). Jakarta: Ikatan Akuntan Indonesia. 
Manahan P, Tampubolon. 2018. Manajemen Operasi dan Rantai Pemasok. Penerbit Mitra Wacana Media, Jakarta.

Martono, Ricky Virona. 2018. Manajamen Operasi Konsep dan Aplikasi. Jakarta: Salemba Empat. Mulyadi. 2014. Sistem Akuntansi. Yogyakarta: Salemba Empat..

Rifqi, Latif Hanafi. 2012. Efisiensi Biaya Pengendalian Bahan Baku Menggunakan Metode Economic Order Quantity (EOQ) Pada PT. Sari Warna Asli V Kudus. Skripsi. Semarang: Fakultas Economi UNNES.

Slamet, Achmad. 2010. Penganggaran Perencanaan dan Pengendalian Usaha. Semarang: UNNES PRESS.

Stice. 2011. Akuntansi Keuangan Intermediate Accounting, Edisi Keenambelas. Diterjemahkan oleh Ali Akbar, Salemba Empat, Jakarta.

Sugiyono. 2012. Metode Penelitian Kuantitatif dan R\&D. Bandung: Alfabeta.

Sunyoto, D. 2012. Manajemen Sumber Daya Manusia. Yogyakarta: CAPS

Sumayang, Lalu. 2010. Dasar-dasar Manajemen Produksi dan Operasi. Jakarta: Salemba Empat

Syamsuddin. 2009. Manajemen Keuangan Perusahaan. Jakarta: PT. Raja Grafindo Persada. 